\title{
Cerebellar Sarcoma
}

National Cancer Institute

\section{Source}

National Cancer Institute. Cerebellar Sarcoma. NCI Thesaurus. Code C66803.

An obsolete term referring to desmoplastic medulloblastoma. 